\title{
Field Assisted Sintering Technique Compaction of Ultrafine-Grained Binderless WC Hard Metals
}

\author{
M. Dopita*, A. Salomon, D. Chmelik, B. Reichelt and D. Rafaja \\ Institute of Materials Science, Technical University of Freiberg, Gustav-Zeuner-Str. 5, 09599 Freiberg, Germany \\ Tungsten carbide (WC) powder having a crystallite size around $55 \mathrm{~nm}$ and the Brunauer-Emmett-Teller \\ specific surface area $2.75 \mathrm{~m}^{2} / \mathrm{g}$ was sintered using the field assisted sintering/spark plasma sintering technique. \\ Sintered samples were investigated using different analytical methods providing detailed information on the \\ microstructure and mechanical properties of materials. Density and porosity of specimens were determined using \\ the Archimedes principle and optical and scanning electron micrographs. The X-ray diffraction investigations \\ provided the information on the crystal real structure and crystallite sizes. The electron backscatter diffraction \\ measurements yielded the details about the grain size, frequency, and distributions of grain boundaries. Finally, \\ the essential mechanical properties of sintered samples were obtained from the hardness and fracture toughness \\ measurements. The influences of individual sintering conditions: sintering temperature and sintering time espe- \\ cially, on the microstructure and mechanical properties of sintered specimens were derived. Fully compact samples \\ having the Vickers hardness HV10 around $29 \mathrm{GPa}$ and fracture toughness $K_{\text {Ic }}$ approximately $7.2 \mathrm{MPa} \mathrm{m}^{1 / 2}$ were \\ sintered from temperatures of $1800{ }^{\circ} \mathrm{C}$ and holding times $1 \mathrm{~min}$. Specimens sintered at lower temperatures showed \\ lower density which resulted in a significant drop in the sample hardness.
}

PACS: 81.05.Je, 81.05.Mh, 81.07.-b, 81.20.-n, 81.20.Ev, 62.20.Qp, 62.20.mm

\section{Introduction}

The WC-Co hard metals are, because of their suitable mechanical properties as high hardness and high fracture toughness simultaneously, the most commonly used materials for the tooling applications, nowadays [1, 2]. The conventional procedures as a classical liquid phase sintering however reached their limits in the preparation of the ultrafine-grained or nanocrystalline materials, especially because of relatively long sintering times in combination with high temperatures which are necessary for the sintering of compact fully dense materials. The problems of long sintering times are significantly reduced using a modern sintering method - field assisted sintering technique (FAST)/spark plasma sintering (SPS).

The presence of ductile metallic binder phase, most frequently cobalt in the $\mathrm{WC}-\mathrm{Co}$ hard metals, has several important consequences on the mechanical properties of material as well as on the densification process. First, the presence of the ductile binder leads to the pronounced drop in the hardness of material and moreover it has in consequence considerable decay of corrosion and oxidation properties, particularly at higher temperatures [3]. On the other hand, the binder phase significantly helps during the densification while sintering close to the melting point of $\mathrm{Co}$, which is extensively lower than melting point of the $\mathrm{WC}\left(2785^{\circ} \mathrm{C}\right)$. Thence it follows that it is nearly impossible to sinter binderless WC using classical sintering procedures. For successful specimen densification a simultaneous temperature and pressure application together with the WC grains surface activation is necessary. Both of those two conditions are successfully satisfied using the spark plasma sintering.

* corresponding author; e-mail: dopita@gmail.com

\section{Experimental}

The commercially available tungsten carbide powder (100 vol.\% WC, space group P-6m2) having the Brunauer-Emmett-Teller BET specific surface area of $2.75 \mathrm{~m}^{2} / \mathrm{g}$ (mean BET grain size $d_{\mathrm{BET}}=139 \mathrm{~nm}$ ) and mean crystallite size determined from the X-ray diffraction measurements of approximately $55 \mathrm{~nm}$ was used in this work. The powder total and free carbon contents due to the vendor specifications were: $C_{\text {total }}=6.14 \%$, $C_{\text {free }}=0.07 \%$, respectively. The oxygen contamination measured using the LECO TC-436 analyzer was 0.26 mass\%.

For the samples sintering the SPS equipment FCT HP D 25/1 [4] was used. WC powder was loaded into the graphite die having the inner diameter of $20 \mathrm{~mm}$ fabricated from high strength graphite. A graphite foil was used to avoid the contact of the powder with the die surface. To minimize the radiation heating losses and to avoid the creation of possible radial temperature gradients the whole graphite sample environment was surrounded with a carbon felt. The specimens were pre-pressed to $25 \mathrm{MPa}$ and heated up by a pulsed electric current with the heating rate of $150^{\circ} \mathrm{C} / \mathrm{min}$ up to $1600^{\circ} \mathrm{C}$ at which temperature the pressure of $80 \mathrm{MPa}$ was applied. Consequently the temperature was increased with heating rate of $150{ }^{\circ} \mathrm{C} / \mathrm{min}$ up to the sintering temperature. After sintering the specimens were cooled down with the cooling rate of $150^{\circ} \mathrm{C} / \mathrm{min}$ to the room temperature with continuous releasing of pressure. The samples series with sintering temperatures 1700,1800 , and $1900^{\circ} \mathrm{C}$ and holding times of 1,3 , and 10 min at sintering temperature was prepared. The sintering procedure was done in vacuum.

Sintered cylindrical samples having the diameter of $20 \mathrm{~mm}$ and height of $5 \mathrm{~mm}$ were cut on two semi-cylinders. Section plane was carefully polished to re- 
move strained surface of material created during cutting and consequently subjected to the detailed investigations. The polishing procedure followed the next steps; first, the specimens were mechanically grinded using silicon carbide grinding plates with decreasing roughness and subsequently polished with $15,6,3$, and $1 \mu \mathrm{m}$ diamond paste. Finally the samples were etched for $90 \mathrm{~s}$ using the OP-S suspension (Struers A/S). The density and porosity of sintered specimens were determined using the Archimedes principle and the image analyses of optical and scanning electron microscope micrographs.

The X-ray diffraction (XRD) measurements were performed using the URD6 diffractometer. The goniometer working in conventional focusing Bragg-Brentano geometry was equipped with the graphite monochromator in the diffracted beam and filtered $\mathrm{Cu} K_{\alpha}$ radiation $(\lambda=0.15418 \mathrm{~nm})$ was used for the measurements. Measured diffraction patterns collected in the angular range $2 \theta=25^{\circ}-150^{\circ}$, with a step of $\Delta 2 \theta=0.04^{\circ}$ and time $10 \mathrm{~s} / \mathrm{step}$ were refined using the full powder pattern refinement (the Rietveld method) to obtain the contents of present phases as well as the detailed information on the real structure of phases. For the Rietveld refinement computer program Maud [5] was used.

The morphology and microstructure were investigated using high-resolution scanning electron microscope (SEM) LEO 1530 equipped with a field emission cathode, with a detector of backscatter electrons (SEM/BSE) and Nordlys II EBSD detector.

Hardness of sintered specimens was measured using the M4U-025 Vickers hardness tester. An indenter load of $10 \mathrm{~kg}$ and indentation time $10 \mathrm{~s}$ were applied. Fracture toughness was determined from the measurements of the Vickers indentation crack lengths applying the theory proposed by Shetty et al. [6].

\section{Results}

\subsection{Sintering characteristics, densification and density}

The first rough information about the sintering process and densification of the samples were obtained from the shrinkage rates (derivative of the pistons displacement corrected for the temperature expansion of graphite sample environment and piston) of the specimen. The powder grains surface activation and consequently the sintering process starts approximately at $1200^{\circ} \mathrm{C}$. Afterwards, with increasing temperature the shrinkage rate increases, reaches its maximum between $1400^{\circ} \mathrm{C}$ and $1700^{\circ} \mathrm{C}$ and subsequently drops down. Finally it reaches the zero value between $1800^{\circ} \mathrm{C}$ and $1900^{\circ} \mathrm{C}$ which in ideal case means no more powder grains movement or rearrangement and the end of the sintering process with $100 \%$ dense specimen.

In Fig. 1a,b relative densities determined using the Archimedes principle and material theoretical densities estimated from the XRD measurements as a function of sintering temperature (Fig. 1a) and time (Fig. 1b) are shown. Relative density of the sample sintered at
$1700{ }^{\circ} \mathrm{C}$ for $1 \mathrm{~min}$ is quite low - around $93 \%$ only. With increasing sintering time the relative density of the sample increases, whereas the increase of the relative density is more obvious with increasing sintering temperature. Specimens sintered at $1700{ }^{\circ} \mathrm{C}$ for 10 min show the relative density more than $99.8 \%$. Finally, samples sintered at temperatures of $1800^{\circ} \mathrm{C}$ and $1900^{\circ} \mathrm{C}$ yield saturated relative density approaching $100 \%$ already after 1 min of holding time.

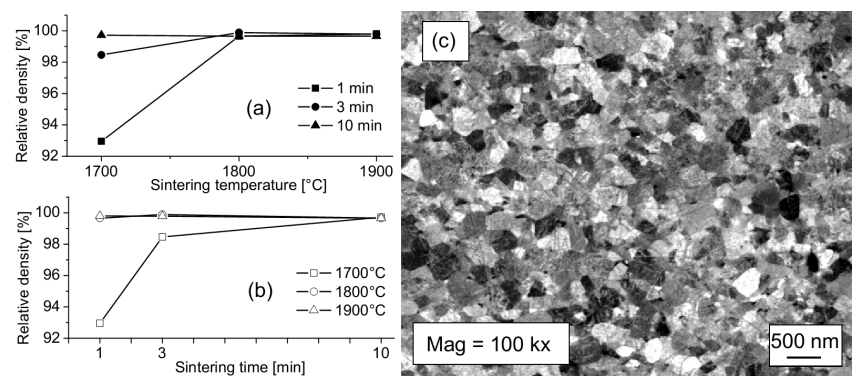

Fig. 1. Plots of the relative densities of sintered specimens as a function of sintering temperature (a) and sintering time (b). SEM/BSE micrograph of the specimen sintered at $1800^{\circ} \mathrm{C}$ for $3 \min (\mathrm{c})$.

In Fig. 1c a scanning electron micrograph acquired in the backscatter electron mode (SEM/BSE) of typical polished specimen morphology is shown. Individual grains (different gray scale corresponds to the different crystallographic orientation of grains) are clearly visible in the micrograph. The porosity usually estimated from the optical or scanning electron microscopy is negligible as no clear pores can be found in the micrograph. Therefore, the common porosity determination based upon comparison of optical or SEM micrographs with standard pictures cannot be applied to our samples and the porosity can only be roughly estimated from the deviation of the relative density from $100 \%$.

\subsection{Phase, crystallite and grain size evolution}

The initial powder contained WC only. During the sintering process second $-\mathrm{W}_{2} \mathrm{C}$ phase (space group $P-31 \mathrm{~m}$ ) was formed in the samples. The formation of minor $\mathrm{W}_{2} \mathrm{C}$ phase was independent on temperature and sintering time, whereas the volume ratio of $\mathrm{WC} / \mathrm{W}_{2} \mathrm{C}$ as determined from the XRD measurements was roughly $98 / 2$ vol.\% in all sintered samples. We suppose that the phase transform of WC into the carbon poorer $\mathrm{W}_{2} \mathrm{C}$ phase is a consequence of the powder oxygen contamination. During the sintering process the oxygen molecules adsorbed on the WC grains surface react with WC transforming some carbon atoms into carbon monoxide and creating carbon poorer $\mathrm{W}_{2} \mathrm{C}$ phase.

In Fig. 2a the evolution of size of coherently diffracting domains (crystallite size) of the WC phase estimated from the XRD as a function of sintering temperature for all three sintering times is shown. In specimens sintered for $1 \mathrm{~min}$ the crystallite size increases from approximately 

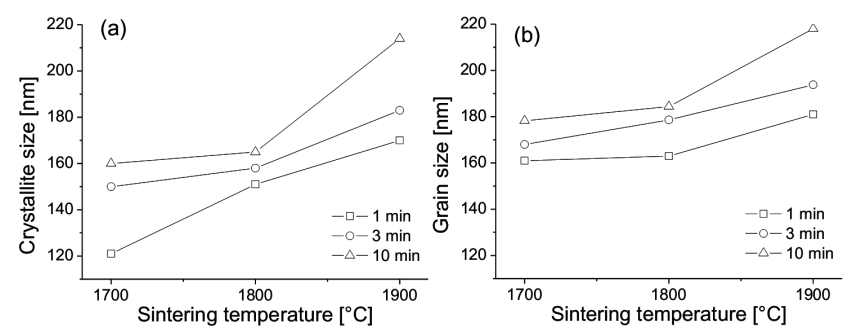

Fig. 2. Evolution of the WC crystallites size as a function of sintering temperature for specimens sintered 1 , 3, and 10 min (a). Evolution of the WC grain size as a function of sintering temperature for specimens sintered 1,3 , and $10 \mathrm{~min}(\mathrm{~b})$.

$120 \mathrm{~nm}$ in sample sintered at $1700^{\circ} \mathrm{C}$ to $165 \mathrm{~nm}$ in sample sintered at $1900^{\circ} \mathrm{C}$. Similar thermal effect on the crystallite growth is obvious in specimens sintered for $3 \mathrm{~min}$, as well. Finally the biggest crystallite size exhibit the specimens sintered for $10 \mathrm{~min}$, where the increase from roughly $160 \mathrm{~nm}$ in sample sintered at $1700^{\circ} \mathrm{C}$ to about $215 \mathrm{~nm}$ in sample sintered at $1900^{\circ} \mathrm{C}$ is clearly visible in the figure.

The grain size of sintered specimen was determined using the line intercept method from the electron backscattering diffraction (EBSD) measurements. The evolution of the grain size as a function of sintering temperature for specimens sintered for 1,3 , and $10 \mathrm{~min}$ is shown in Fig. 2b. The grain size evolution follows the evolution of the crystallite size since both two effects - grain and crystallite growth are the thermally activated processes. However, the grain growth is only moderate in comparison to the crystallite growth (compare Fig. 2a,b) and as it is clearly visible in Fig. $2 \mathrm{~b}$ the main grain growth occur in specimens between $1800^{\circ} \mathrm{C}$ and $1900{ }^{\circ} \mathrm{C}$. Finally the grain size of specimen sintered for $10 \mathrm{~min}$ at $1900^{\circ} \mathrm{C}$ is around $220 \mathrm{~nm}$ which well corresponds to the crystallite size of that specimen.

As it follows from comparison of grain and crystallite sizes of not well sintered specimen $\left(1700^{\circ} \mathrm{C}\right.$ for $\left.1 \mathrm{~min}\right)$, the individual grains of initial powder containing lots of lattice defects consist of more crystallites separated by low angle grain boundaries. With increasing sintering temperature the lattice defects (originally creating the low angle grain boundaries) annihilate and individual crystallites grow. Finally, the specimens sintered at $1900^{\circ} \mathrm{C}$ contain very few lattice defects and the crystallite size roughly corresponds to the grain size - or by the other words each grain contains approximately one crystallite.

The EBSD mapping confirmed the equiaxed homogeneous morphology of the WC grains and as it is expected for sintered specimens no preferred orientation of crystallites (texture) was observed in samples. Besides, the EBSD measurement revealed high fraction of special high angle grain boundaries - coincidence sites lattice (CSL) $\Sigma 2$ and $\Sigma 4$ grain boundaries [7, 8]. The length fractions of $\Sigma 2$ and $\Sigma 4$ grain boundaries in sintered specimens are in the range of $10 \%$ and $3 \%$, respectively and depend neither on the sintering temperature nor on the sintering time.

\subsection{Hardness and fracture toughness}

The evolution of measured Vickers hardness HV10 as a function of sintering time and temperature is shown in Fig. 3a,b, respectively. In samples sintered at $1700^{\circ} \mathrm{C}$ the hardness significantly changes with increasing sintering time. Steep increase is evident between 1 and $3 \mathrm{~min}$ of sintering mainly, whereas the variation in the hardness is only negligible after $3 \mathrm{~min}$ of sintering. The hardness of specimens sintered at $1800^{\circ} \mathrm{C}$ and $1900{ }^{\circ} \mathrm{C}$ does not significantly change with sintering time. The hardness changes with increasing sintering temperature are obvious in the specimens sintered for $1 \mathrm{~min}$, where steep hardness increase between samples sintered at $1700^{\circ} \mathrm{C}$ and $1800^{\circ} \mathrm{C}$ is clearly seen in the plot. Finally, the highest Vickers hardness HV10 in all samples under study, approximately $29 \mathrm{GPa}$, was observed in specimen sintered at $1800^{\circ} \mathrm{C}$ for $10 \mathrm{~min}$.
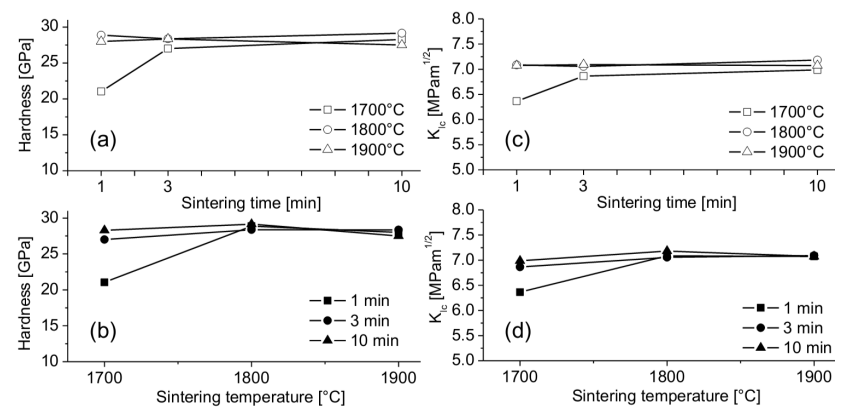

Fig. 3. Evolution of measured Vickers hardness HV10 as a function of sintering time (a) and sintering temperature (b). The dependence of the fracture toughness $K_{\text {Ic }}$ on the sintering time (c) and sintering temperature (d).

In Fig. 3c,d plots of the fracture toughness $K_{\text {Ic }}$ versus sintering time and sintering temperature are shown. The temperature and time evolution of the fracture toughness follows similar trends as described for the material hardness. Fracture toughness increases with increasing sintering time in specimen sintered at $1700^{\circ} \mathrm{C}$, only. In samples sintered at $1800^{\circ} \mathrm{C}$ and $1900^{\circ} \mathrm{C}$ the fracture toughness is saturated and does not significantly vary with sintering time. The evolution of fracture toughness with increasing sintering temperature is pronounced between $1700^{\circ} \mathrm{C}$ and $1800^{\circ} \mathrm{C}$ where it reaches its maxima and is not further changing with increasing sintering temperature. The highest fracture toughness $K_{\text {Ic }}$, roughly $7.2 \mathrm{MPa} \mathrm{m}^{1 / 2}$, yields the sample sintered at $1800^{\circ} \mathrm{C}$ for $10 \mathrm{~min}$.

\section{Discussion}

Sintered specimens relative density strongly depends on the sintering temperature and time. Samples sintered at $1700{ }^{\circ} \mathrm{C}$ for 1 and 3 min show the lowest relative 
density, which implicates a higher porosity of samples. In specimens sintered at $1800{ }^{\circ} \mathrm{C}$ and $1900^{\circ} \mathrm{C}$ the relative density is saturated already after $1 \mathrm{~min}$ of sintering having value of $99.8 \%$ and does not significantly change with increasing sintering time. Mechanical properties, the hardness and fracture toughness, of sintered specimens correlate strongly with relative densities (compare Figs. 1 and 3) - the higher the density is the better are the values of hardness and fracture toughness.

Sintered specimens contain about 98 vol.\% of WC and 2 vol.\% of $\mathrm{W}_{2} \mathrm{C}$. The phase composition is independent of the sintering conditions and does neither correlate with other microstructural properties nor mechanical parameters. The $\mathrm{W}_{2} \mathrm{C}$ is a hard phase as well and 2 vol.\% only cannot significantly change the mechanical properties of samples.

The sintering temperature is the leading factor influencing strongly the crystallite and the grain growth. With increasing sintering temperature the crystallite and the grain size of dominant WC phase increases radically and reach approximately $220 \mathrm{~nm}$ in specimen sintered at $1900{ }^{\circ} \mathrm{C}$ for $10 \mathrm{~min}$. The $200 \mathrm{~nm}$ is the value accepted in the hard metal community as a boundary between nanoand ultrafine-grained materials.

Owing to described difficulties concerning the binderless WC sintering, only few works were done so far on the sintering of nanocrystalline or ultrafine-grained binderless WC [9-13]. Moreover, it is rather hard task to compare published results with ours, since other authors used different starting powders and various sintering equipments which resulted in diverse definition of sintering conditions. Kim and coworkers [9] referred to the binderless WC having the relative density $97.6 \%$, grain size $400 \mathrm{~nm}$, hardness of $24.8 \mathrm{GPa}$ and fracture toughness 6.6 $\mathrm{MPa} \mathrm{m} \mathrm{m}^{1 / 2}$, while Huang et al. [11] sintered samples with relative density $99.9 \%$, grain size $280 \mathrm{~nm}$, hardness of $27.4 \mathrm{GPa}$ and fracture toughness $4.4 \mathrm{MPa} \mathrm{m}^{1 / 2}$. In our previous work [13] we referred to the SPS sintering of nanopowder resulting in material having the crystallite size below $200 \mathrm{~nm}$, hardness $30 \mathrm{GPa}$ and fracture toughness $7.3 \mathrm{MPa} \mathrm{m} \mathrm{m}^{1 / 2}$.

From direct comparison of those results it is clear that the crystallite and grain sizes of sintered dense sample are fundamental parameters influencing the mechanical properties of material. Our current results discussed in this work: grain size $220 \mathrm{~nm}$, hardness $29 \mathrm{GPa}$ and fracture toughness $7.2 \mathrm{MPa} \mathrm{m} \mathrm{m}^{1 / 2}$ match well between the results published by Huang et al. [11] and our previous work [13].

\section{Conclusions}

Binderless WC hard metals were sintered from ultrafine-grained powder using the SPS. The influences of sintering conditions - temperature and sintering time on the microstructure and mechanical properties of sintered specimens were derived. Correlation between individual microstructural and mechanical properties were discussed. The fully compact (relative density $\approx 99.8 \%$ ) samples having the Vickers hardness HV10 around $29 \mathrm{GPa}$ and fracture toughness $K_{\text {Ic }}$ approximately $7.2 \mathrm{MPa} \mathrm{m}{ }^{1 / 2}$ were sintered from temperatures of $1800{ }^{\circ} \mathrm{C}$ and holding times $1 \mathrm{~min}$. Specimens sintered at lower temperatures showed lower density, which resulted in a significant drop in the sample hardness.

\section{Acknowledgments}

This work was financially supported by the German Scientific Council (DFG) as part of a research project within the Collaborative Research Centre SFB 920. The authors would as well like to acknowledge the financial support through the Dr. Erich-Krüger-Stiftung, this is subproject \#8 from Freiberg High-Pressure Research Centre FHP.

\section{References}

[1] G. Gille, B. Szesny, K. Dreyer, H. van den Berg, J. Schmidt, T. Gestrich, G. Leitner, Int. J. Refr. Metals Hard Mater. 20, 3 (2002).

[2] Z.Z. Fang, X. Wang, T. Ryu, K.S. Hwang, H.Y. Sohn, Int. J. Refr. Metals Hard Mater. 27, 288 (2009).

[3] H. Suzuki, in: Cemented Carbide and Sintered Hard Materials, Maruzen Publishing Company, Tokyo 1986, p. 262.

[4] FCT Systeme GmbH, webpages: http://www.fct-systeme.de/.

[5] L. Lutteroti, MAUD, IUCR Commission for Powder Diffraction, CPD Newsletter (IUCr), 21, 1999.

[6] D. Shetty, I.G. Wright, P.N. Mincer, A.H. Clauer, J. Mater. Sci 20, 1873 (1985).

[7] M. Dopita, D. Rafaja, H.J. Seifert, D. Janisch, W. Lengauer, in: Proc. 17th Int. Plansee Seminar, Eds. L.S. Sigl, P. Rödhammer, H. Wildner, Vol. 3, AT4, Plansee Group, Reutte (Austria) 2009.

[8] M. Dopita, D. Rafaja, D. Chmelik, A. Salomon, D. Janisch, W. Lengauer, Materials Structure 18, 169 (2011).

[9] H.-C. Kim, I.-J. Shon, J.E. Garay, Z.A. Munir, Int. J. Refr. Metals Hard Mater. 22, 257 (2004).

[10] L. Girardini, M. Zadara, F. Casari, A. Molinari, Metal. Powder Report 63, 18 (2008).

[11] S.G. Huang, K. Vanmeensel, O. van der Biest, J. Veleugels, Int. J. Refr. Metals Hard Mater. 26, 41 (2008).

[12] J. Zhang, G. Zhang, A. Zhao, X. Song, J. Alloys Comp. 479, 427 (2009).

[13] M. Dopita, C.R. Sriram, D. Chmelik, A. Salomon, H.J. Seifert, in: Proc. 2nd Int. Conf. NANOCON 2010, A46, Tanger Ltd., Ostrava (Czech Republic) 2010 . 